\title{
Experimental Research on a Novel Solution Regeneration System for Heat Source Tower Based on Vacuum Boiling and Condensation
}

\author{
Xiantai Wen, Xianqi Cao, Pengfei Yu and Jiao Yu
}

Heat source tower heat pump (HSTHP) system is drawing more and more attention in Yangtze River Region, China, due to its energy saving characteristics. However, solution dilution occurs when it operates in the heating mode in winter. A high efficiency solution regeneration of heat source tower based on integration of vacuum boiling and condensation is proposed, and the relative experimental setup is built. The effects of inlet solution concentration, inlet solution temperature, system vacuum value and electric heater outlet valve open time on the performance of its regeneration efficiency and rate are studied. The results show that the regeneration efficiency of the novel system can achieve as high as $4.75 \mathrm{~kg}$ $\mathrm{kWh}^{-1}$. Compared with the electric heating regeneration method $\left(1.44 \mathrm{~kg} \mathrm{kWh}^{-1}\right)$, this regeneration system shows a great energy saving potential.

Keywords: Heat source tower; Solution regeneration; Regeneration efficiency; Regeneration rate; Vacuum boiling and condensation

Received 5 October 2018, Accepted 6 November 2018

DOI: $10.30919 / \mathrm{esee} 8 \mathrm{c} 175$

\section{Introduction}

The Yangtze River Region in China is characterized by wet and hot summers, and wet and cold winters. ${ }^{1}$ In this region, the heat source tower heat pump (HSTHP) system is drawing more and more attention due to its advantages over the conventional heating and cooling systems (e.g. air-source heat pump). ${ }^{2}$ In summer, the HSTHP has high cooling efficiency like cooling tower assisted chiller. And in winter, it takes air as a low-grade heat source, which improves the ratio of energy utilization and energy efficiency. Liang et $a l^{3.4}$ studied the performance of the HSTHP by altering the circulating solution temperature differences. They found that the COP of the HSTHP increased from 2.72 to 3.02 . Lu et al. ${ }^{5}$ analyzed the heat and mass transfer characteristics of a counter-flow heat source tower and the numerical model of the tower operating in winter was validated by experimental results. Wen et al..$^{6-9}$ studied the characteristics of heat-source tower and its heat pump system, whose heat and mass transfer coefficient was gotten by experiments and simulation. The optimized liquid to gas ratio was studied under both the cooling mode and heating mode. Li et al. ${ }^{10}$ experimental studied the closed heat source tower heat pump system. Results showed that this system can be operated efficiently in low temperature condition. The HSTHP is an energy-saving heat pump system which is suitable for Yangtze River Region. However, when it operates in winter, both heat and mass transfer occur and the vapor in the air can be absorbed into the solution. The concentration can be diluted, which makes the freezing point temperature rise, in turn resulting an increasing risk of system freeze. Therefore, an apparatus for

School of Energy and Power Engineering, Nanjing Institute of Technology, Nanjing211167, P.R. China

*E-mail: wenxiantai@njit.edu.cn solution regeneration is significantly important to be involved in the system.

Heating evaporation regeneration is a widely used method for solution regeneration. Water in the solution is vaporized and transferred into the atmosphere to realize solution regeneration. As for packing towers, Liu et al. ${ }^{11}$ studied the heat and mass transfer process under different flow patterns (counter flow, cross flow and parallel flow) and different heating methods (air heating and solution heating). Kim et al. ${ }^{12}$ established simplified model of solution regeneration system with packed tower. Results showed that the model was highly align with the experiments and had strong application value. Zhang et al. ${ }^{13-14}$ experimental studied the heat and mass transfer ability of counter flow tower, and analyzed the irreversible process of the whole system under different conditions. As for falling film tower, the heat and mass transfer process under different air flow arrangements and under different heat source types were analyzed. ${ }^{15-17}$ Simultaneously, solar heat and other waste heat can also be used for regeneration. Peng et al. ${ }^{18}$ established the model of solar solution regeneration and solution dehumidification system. Besides, more and more scholars are concentrated on heating evaporation regeneration. ${ }^{19-21}$

Electrodialysis is a kind of the membrane separation technology, and the electrolyte is separated from solution by the characteristic of permselectivity membrane. Cheng et $a l^{22-23}$ investigated actual effect of concentration difference between dilute and regenerate cells on the performance of electrodialysis regenerator by experiments. Farrell et $\mathrm{al}^{24}$ applied reverse electrodialysis and desalination technology to a sustainable greenhouse system. Li et al..$^{25-26}$ put forward electrodialysis integrated photovoltaic system and carried on relative researches. Results showed that the regeneration efficiency was improved $100 \%$ compared with traditional heating regeneration. Besides, more researchers were also concentrated on the electrodialysis regeneration. ${ }^{27-30}$ However, the regeneration method is proposed for the separation of electrolyte solution, which cannot be used for the non-electrolyte 
solution (e.g.ethylene glycol).

Vacuum boiling is another alternative regeneration method, in which water is separated from the solution by boiling and condensation. Many scholars carried out theoretical and experimental researches and results showed that this regeneration method has better energy saving ratio and was widely used in the industrial applications. ${ }^{21-33}$ Concentrated

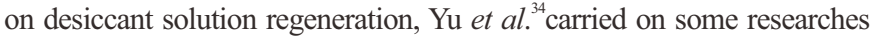
on the boiling characteristic of desiccant solution outside of stainless steel tube under the vacuum condition. Besides, many experiments are carried out to analyze the effect of different running conditions (e.g.solution concentration, vacuum pressure, temperature) on the heating efficiency. ${ }^{35-36}$ The above studies are mainly concentrated on the vacuum boiling characteristics of the dehumidifying saline solution, while the research on the cryogenic antifreeze solution is little considered.

In the HSTHP, the circulation solution is used to prevent system from frozen in winter. Due to the disadvantages of the existing regeneration approaches, the novel solution regeneration method based on integration of vacuum boiling and condensation is proposed. The characteristic of vacuum boiling regeneration in the chemical field is introduced. The vapor condensation in the finned tube surface is integrated with the vacuum boiling process to realize the separation of solution and water. Therefore, the solution regeneration process of heat source tower is the process of separation of solution and water in fact. The efficiency of solution regeneration can be improved greatly. This paper experimentally studies the novel solution regeneration based on vacuum boiling and condensation. The effects of times, solution concentration and inlet solution temperature on the performance are investigated, and the optimized parameters are studied.

\section{Operating process of solution regeneration system for heat source tower}

\subsection{Schematic of the solution regeneration system}

The system diagram of the novel solution regenerator for heat source tower is shown in Fig. 1.

There are four steps for the proposed system: vacuum pumping, operation, discharging condensate water, and discharging solution. The details of each step is shown as follows.

Vacuum pumping (Step 1): the vacuum pump and solenoid valves 3,5,7 are opened first. Then, the solenoid valve 6 is opened in about five seconds. When the vacuum pressure of the system reaches the set value, the solenoid valve 5,6,7, and vacuum pump will be closed. At the end of this mode, only the solenoid valve 3 is open.

Operation (Step 2): the electric heater and solenoid valve 1 are opened first. When the temperature of the electric heater reaches the set value, the solenoid valve 7 is opened in about ten seconds. When the heater temperature reaches the set value again, the solenoid valve 7 is opened.

\begin{tabular}{|l|l|l|}
\hline 1 solelnoid valve 1 & 2 solelnoid valve 2 & 3 solelnoid valve 3 \\
\hline 4 solelnoid valve 4 & 5 solelnoid valve 5 & 6 solelnoid valve 6 \\
\hline 7 solelnoid valve 7 & 8 pump & 9 vacuum pump \\
\hline 10 electric heater & 11 vacuum meter & \\
\hline
\end{tabular}

Discharging condensate water (Step 3): solenoid valve 5,6 and vacuum pump open first. When the flow velocity of water in the pumping pipe reaches stability, the vacuum pump and solenoid valve 5,6 are closed.

Discharging solution (Step 4): both the electric heater and the solenoid valve 1,3,4,5,6,7 are closed, meanwhile both the solenoid valve

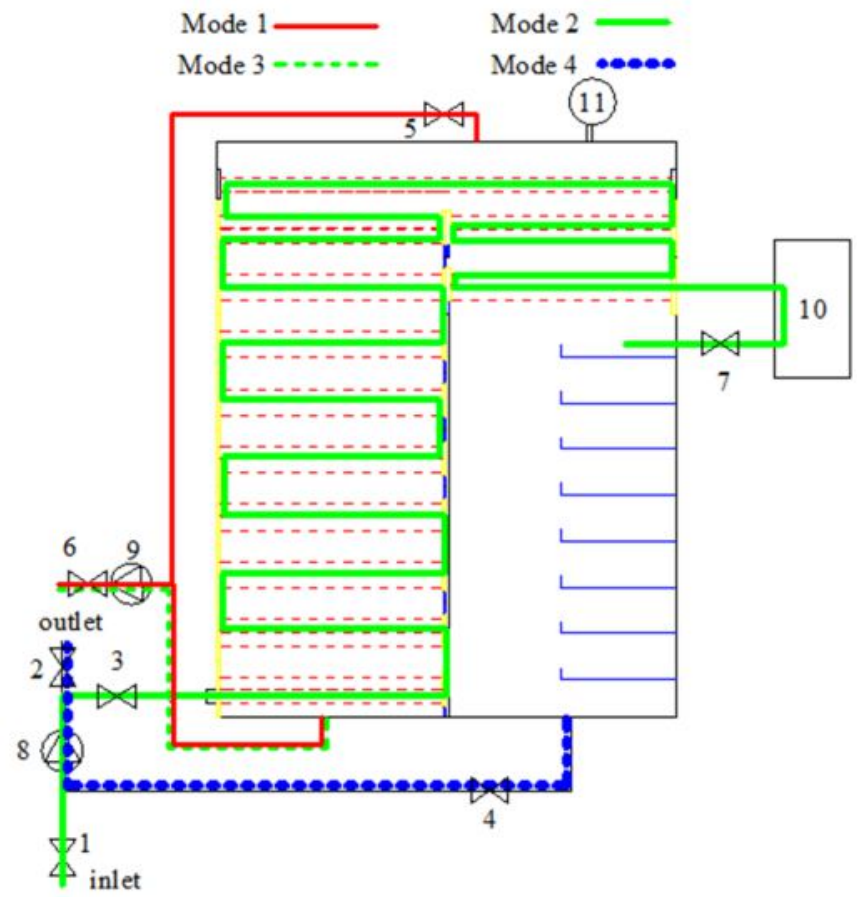

Fig. 1 Schematic of solution regeneration system for heat source tower.

2 and pump are opened. When the solution level is lower than the low liquid level alarm value, the discharge mode ends, and the whole solution regeneration cycle is completed.

\subsection{Heat and mass transfer mathematical model}

\subsubsection{Finned-tube condensation model}

Under the vacuum condition, saturated vapor condenses into water on the surface of finned-tube. Low temperature dilute solution absorbs condensation heat and then flows into the electric heater with its temperature increasing greatly.

The heat transfer rate is calculated as follows:

$$
d Q_{c}=C_{p} G_{s} d t_{s}=K A d t_{m}=r_{s a} d G_{s a}
$$

The total heat transfer coefficient is calculated as follows:

$$
\frac{1}{K}=\frac{1}{h_{c o}} \frac{A_{o}}{A_{i}}+\frac{\mathrm{S}}{l} \ln \frac{A_{o}}{A_{i}}+\frac{1}{h_{c i} h_{o}}
$$

The average heat transfer coefficient outside the pipe is calculated as follows:

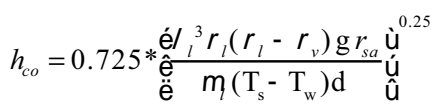

The convective heat transfer coefficient in the pipe is calculated as follows:

$$
h_{c i}=\frac{l}{d} 0.023 \mathrm{Re}^{0.8} \operatorname{Pr}^{0.4}
$$

\subsubsection{Boling room model}

High temperature solution in the electric heater flows into the boiling room. Water in the solution is vaporized outside of the solution and then flows into finned-tube condensation. 
The released heat of solution in the boiling heat transfer process is calculated. The heat transfer rate is calculated as follows:

$$
Q_{e}=C_{p} G_{s} d t_{s}=q_{e} d A
$$

The heat flux in the boiling room is calculated as follows:

$$
q_{e}=X r_{s a}\left(\frac{2 p \mathrm{R}_{\mathrm{g}} \mathrm{T}_{\mathrm{s}}}{M}\right)^{-0.5}\left(\mathrm{p}_{1}-\mathrm{p}_{\mathrm{v}}\right)
$$

\subsubsection{Heat transfer process}

Heat transfer process of solution regeneration system is shown as Fig. 2. Inlet low temperature dilute solution $\left(\mathrm{T}_{\mathrm{si}}\right)$ is absorbed into the finned tube under vacuum condition. Through water vapor condensation in the surface and vacuum condition, the dilute solution flows into electric inlet with temperature increased into $\mathrm{T}_{\mathrm{ei}}$. The dilute solution temperature is improved into $\mathrm{T}_{\mathrm{e}}$ by heater and flows into the salver. Under the vacuum condition, the water in the dilute solution rushes out by boiling and takes away heat form solution with its temperature decreases into $\mathrm{T}_{\mathrm{so}}$. The regeneration efficiency is defined as the amount of condensate produced by unit power consumption $(\mathrm{kg} / \mathrm{kWh})$. In the case of loss, it can be calculated as follows:

$$
q=\frac{T_{e i}-T_{s i}}{T_{e o}-T_{s i}} \frac{3600}{r}
$$

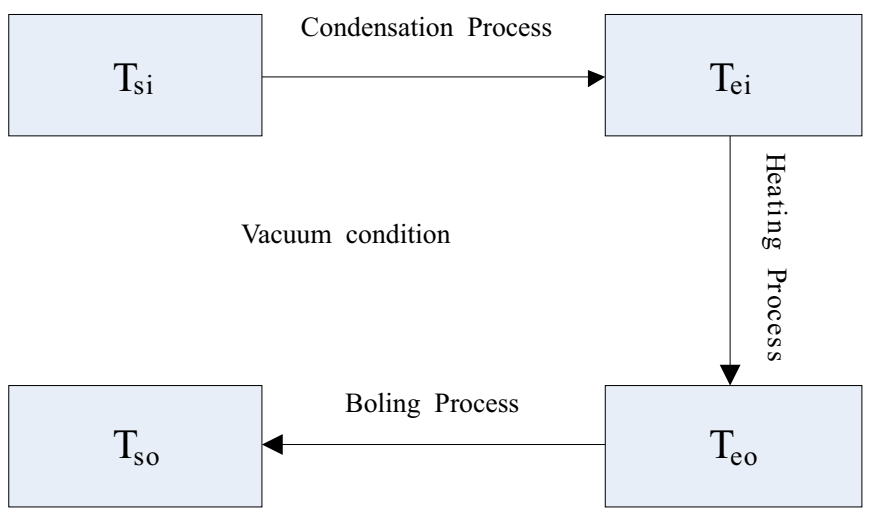

Fig. 2 Heat transfer process of solution regeneration system.

Using this solution regeneration system, only a small amount of driving heat is needed. Heat produced by the boiling process of water is absorbed into the finned tube heat exchanger. Therefore, the solution regeneration process can be seen as separation of water and solution, and the regeneration efficiency is quite high.

\section{Experimental setup}

The novel solution regeneration setup for heat source tower is shown in Fig. 3. The system components mainly includes finned tube, water ring vacuum pump, self-priming pump, electric heater, related connecting pipes and electronic control equipments. The stainless steel plus aluminum finned-tubes are selected in the test. The inner diameter of stainless steel is $16 \mathrm{~mm}$ and the outer diameter of stainless steel is 32 $\mathrm{mm}$. The fins spacing is $2.8 \mathrm{~mm}$ and the pipe shell total area considering ribbed tube is $136.5 \mathrm{~m}^{2}$. Four salvers with $0.12 \mathrm{~m}^{2}$ of each salver is set to increase the surface area of boiling heat transfer.

The key parameters of the solution regeneration system are running time, temperature, the amount of circulating water and condensate water, system vacuum value and solution concentration. The running time is gotten from 34970 data acquisition instrument. The temperature is measured by PT1000 (the measuring accuracy is \pm 0.1 $\left.{ }^{\circ} \mathrm{C}\right)$. The circulating water and condensate water are measured by high precision table weighing (the measuring accuracy is $\pm 0.1 \mathrm{~kg}$ ). The system vacuum value is measured by the vacuum meter. Power consumption is measured by DSSD331 kilowatt-hour meter (the measuring accuracy is $\pm 0.1 \mathrm{kWh}$ ).

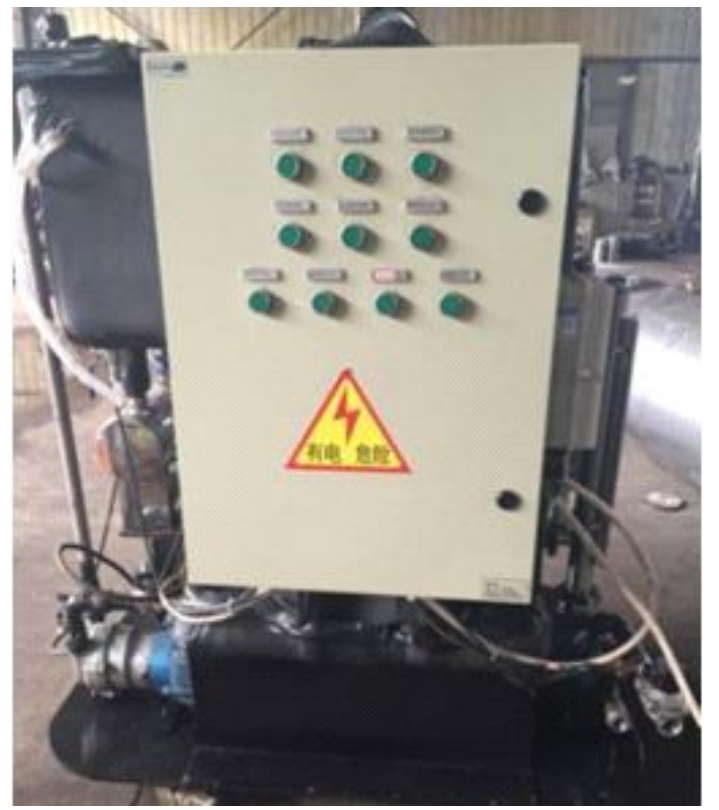

Fig. 3 Equipment of heat-source tower solution regeneration.

Regeneration efficiency is defined as the amount of condensate water produced by unit power consumption $\left(\mathrm{kg} \mathrm{kWh}^{-1}\right)$; Regeneration rate is defined as the amount of condensate water produced per unit time $\left(\mathrm{kg} \mathrm{d}^{-1}\right)$. By changing operation condition, regeneration efficiency and rate are measured, and its change regulations are studied.

\section{Experimental results and discussion}

In this solution regeneration system, water in the ethylene glycol aqueous solution boils in vacuum condition, the resulting water vapor is in contact with the surface of the lower temperature finned tube and is condensed into water. In order to study the process and characteristics of solution regeneration in vacuum condition, theoretical analysis and experimental tests are carried out.

\subsection{Performance under initial unsteady condition}

In this condition, the inlet water temperature is $48^{\circ} \mathrm{C}$, and the vacuum pressure of the system is 0.83 bar. The valve is fully open, and the valve opening time is $11 \mathrm{~s}$. The outside water temperature of the electric heater is set at $95{ }^{\circ} \mathrm{C}$. The following is the theoretical analysis of the data obtained by the experiments.

\subsubsection{Variation of condensate water and power consumption}

According to Fig. 4, with the increase of running times, the power consumption is decreased, while the condensate water is increased, and the system tends to be stable. Initially, the power consumption and condensate water of the system are $3.0 \mathrm{kWh}$ and $2.686 \mathrm{~kg}$ respectively. When the system operates in stable state, power consumption is reduced to $1.8 \mathrm{kWh}$, and condensate water is increased to $5.331 \mathrm{~kg}$. The reason for this phenomenon is that the system is not preheated in the initial 
operation, and part of the heat is used for system heating. Therefore, the demand for heat supply is increased. Simultaneously the boiling efficiency and condensation efficiency are reduced. The power consumption is high and condensate water is low. However, with the increase of the running times, the boiling condensation effect is enhanced after the system is fully preheated, so power consumption is reduced, and condensate water is increased.

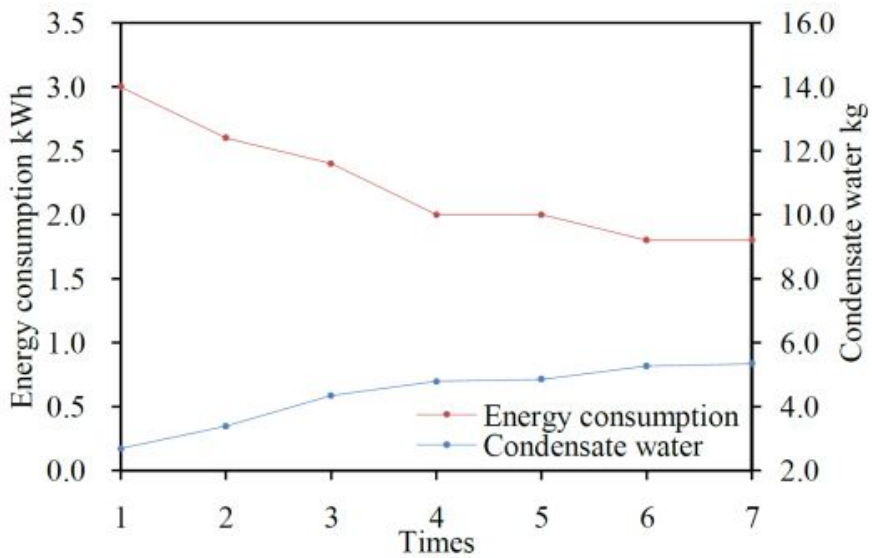

Fig. 4 Condensate water rate and energy consumption with running times.

\subsubsection{Variation of regeneration efficiency and rate}

According to Fig. 5, the regeneration efficiency and rate are increased obviously with the increase of running times. The regeneration efficiency increases from $0.90 \mathrm{~kg} \mathrm{kWh}^{-1}$ to $2.96 \mathrm{~kg}$ $\mathrm{kWh}^{-1}$, and the regeneration rate increases from $198.5 \mathrm{~kg} \mathrm{~d}^{-1}$ to 598.1 $\mathrm{kg} \mathrm{d}^{-1}$. The reason for this phenomenon is that with the increase of operation times, the system is effectively preheated, the condensing water is rapidly increased and gradually stabilized, and the energy generated by the condensation process is transferred effectively. Therefore, the regeneration efficiency and rate are improved greatly.

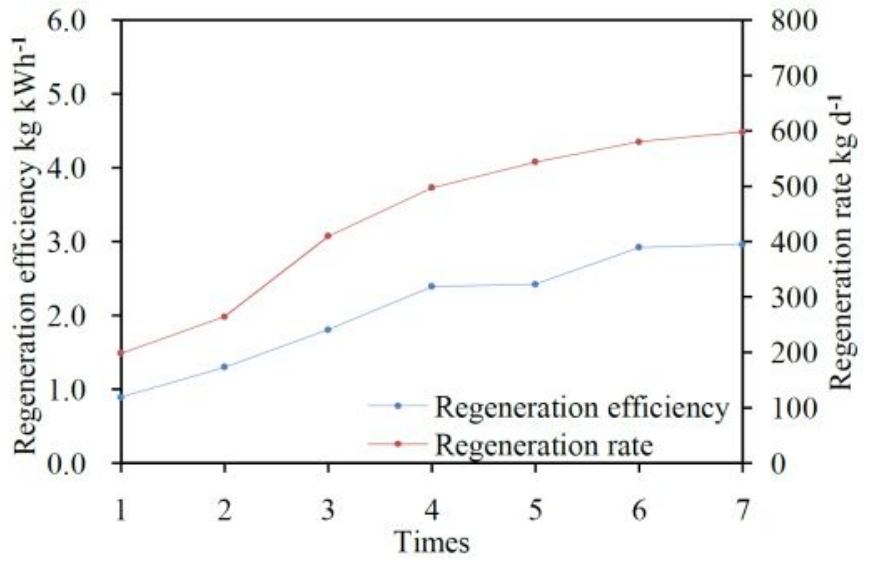

Fig. 5 Regeneration efficiency and rate with running times.

\subsection{Performance of regeneration system \\ 4.2.1 Performance of regeneration system with water as working medium}

(1) Performance with different opening time of outlet valve of

\section{electric heater}

In this condition, the vacuum value is 0.80 bar, and the temperature of electric heater is $95{ }^{\circ} \mathrm{C}$. Simultaneously the valve is all open, and the inlet water temperature is $18^{\circ} \mathrm{C}$. By changing the opening time of outlet valve of electric heater from $8 \mathrm{~s}$ to $13 \mathrm{~s}$, the required time, condensate water and power consumption are recorded, and the regeneration efficiency and rate are calculated as shown in Fig. 6.

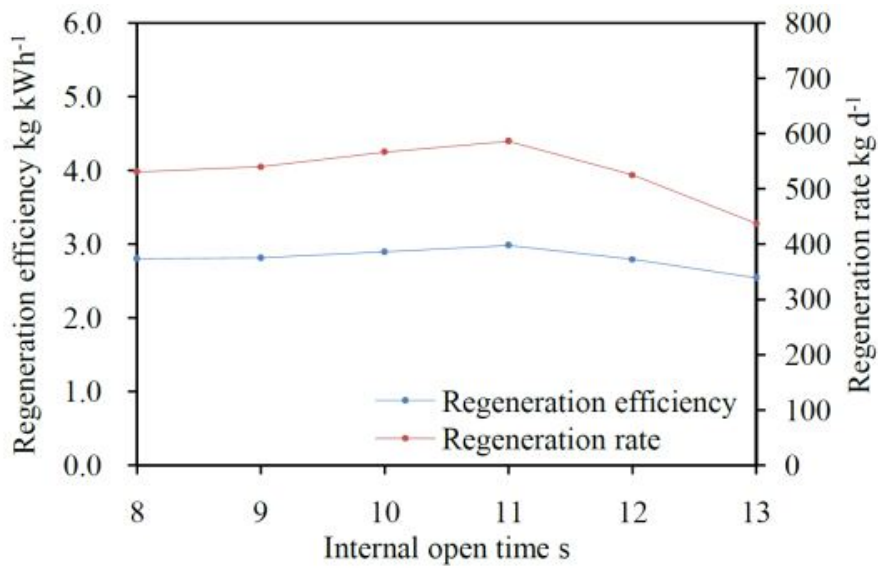

Fig. 6 Regeneration efficiency and rate with different internal open time of outlet valve.

As can be seen from Fig. 6, with the increase of internal open time, the regeneration efficiency and rate are increased first and then decreased. When the internal open time is $8 \mathrm{~s}$, the regeneration efficiency and rate of the system are $2.80 \mathrm{~kg} \mathrm{kWh}^{-1}$ and $530.7 \mathrm{~kg} \mathrm{~d}^{-1}$ respectively. When the internal open time is increased to $11 \mathrm{~s}$, both the regeneration efficiency and rate reach at the maximum value, $2.98 \mathrm{~kg}$ $\mathrm{kWh}^{-1}$ and $585.8 \mathrm{~kg} \mathrm{~d}^{-1}$ respectively. When the internal open time is further increased to $13 \mathrm{~s}$, the two parameters are reduced to $2.54 \mathrm{~kg}$ $\mathrm{kWh}^{-1}$ and $437.1 \mathrm{~kg} \mathrm{~d}^{-1}$ respectively. The reason for this phenomenon is that with the increase of internal open time, the amount of dilute solution inhales is increased, resulting in the increase of the demand for heating and the power consumption. The condensate water quantity increases with the increase of the dilute solution intake. Thus, the regeneration efficient and rate have the maximum value.

(2) Performance with different inlet water temperature

In this condition, the vacuum value is 0.80 bar, and the temperature of electric heater is $95{ }^{\circ} \mathrm{C}$. Simultaneously the valve is all open, and the internal open time is $11 \mathrm{~s}$. By changing the inlet water

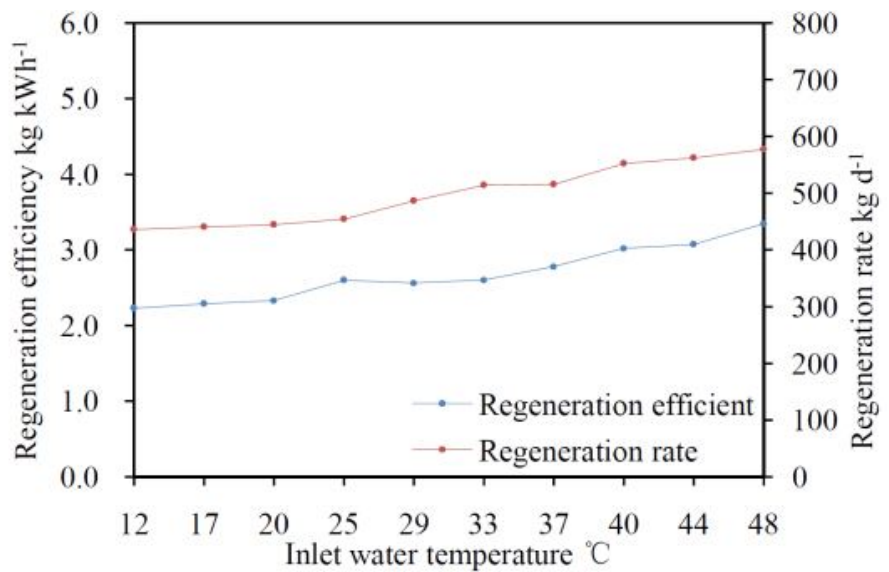

Fig. 7 Regeneration efficiency and rate with different inlet water temperature. 
temperature from $12^{\circ} \mathrm{C}$ to $48^{\circ} \mathrm{C}$, the required time, the condensate water and the power consumption are recorded, and the regeneration efficiency and rate are calculated as shown in Fig. 7.

As can be seen from Fig. 7, the regeneration efficiency and rate show an upward trend with the increase of inlet water temperature. Initially, the regeneration efficiency and rate are $2.23 \mathrm{~kg} \mathrm{kWh}^{-1}$ and $436.1 \mathrm{~kg} \mathrm{~d}^{-1}$ respectively. When the inlet water temperature increases at $48{ }^{\circ} \mathrm{C}$, the regeneration efficiency and rate are increased at $3.35 \mathrm{~kg} \mathrm{kWh}^{-1}$ and $577.6 \mathrm{~kg} \mathrm{~d}^{-1}$ respectively. The reason for this phenomenon is that with the increase of inlet water temperature, the electricity consumption decreases, and the condensate water fluctuates between $4.6 \mathrm{~kg}$ and 4.9 $\mathrm{kg}$ (always higher than the initial value). The operation time of the system decreases, so the regeneration efficiency and rate show an upward trend.

\section{(3) Performance with different vacuum condition}

In this condition, the inlet water temperature is $48{ }^{\circ} \mathrm{C}$, and the temperature of electric heater is $95{ }^{\circ} \mathrm{C}$. Simultaneously the valve is all open, and the internal open time is 11s. By changing the vacuum degree of the system from 0.90 bar to 0.77 bar, the required time, the condensate water and the power consumption are recorded, and the regeneration efficiency and rate are calculated as shown in Fig. 8.

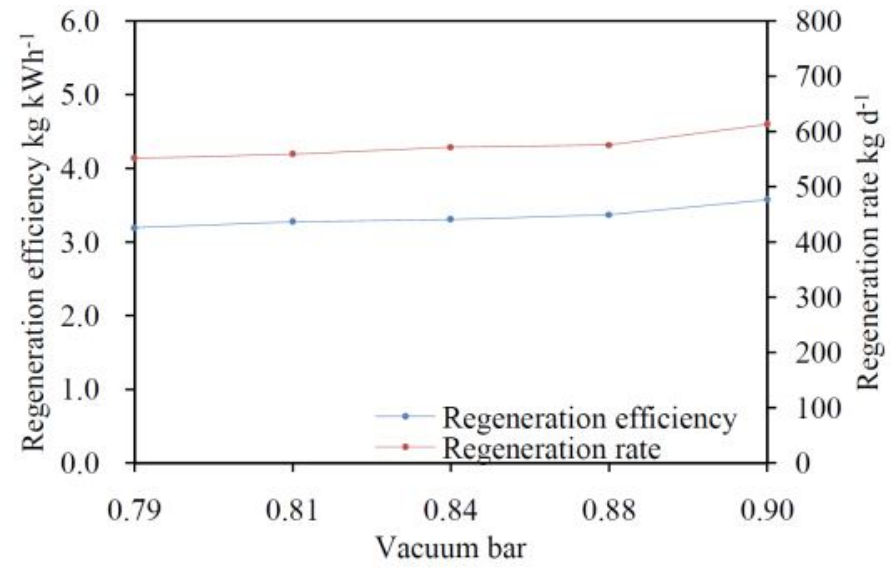

Fig. 8 Regeneration efficiency and rate with different vacuum degree.

As can be seen from Fig. 8, with the increase of vacuum degree, the regeneration efficiency and rate are increased gradually. Initially, the regeneration efficiency and rate are $3.19 \mathrm{~kg} \mathrm{kWh}^{-1}$ and $551.5 \mathrm{~kg} \mathrm{~d}^{-1}$ respectively, and then increase gradually. When the system vacuum rises to $0.90 \mathrm{bar}$, the regeneration efficiency and rate reach the highest value (3.57 kg kWh${ }^{-1}$ and $613.1 \mathrm{~kg} \mathrm{~d}^{-1}$ respectively). The reason for this phenomenon is that with the increase of vacuum degree, the degree of water boiling decreases and the superheat of water vapor increases. Therefore the regeneration efficiency and rate are obviously improved.

\subsubsection{Performance of regeneration system with glycol aqueous solution as working medium \\ (1) Performance with different outlet valve of electric heater}

In this condition, the inlet solution temperature is $30{ }^{\circ} \mathrm{C}$, and the concentration of solution is $30 \%$. The outside water temperature of the electric heater is set at $95{ }^{\circ} \mathrm{C}$ and the vacuum pressure of the system is 0.83 bar. By changing the opening time of the outlet valve of the electric heater from $9 \mathrm{~s}$ to $13 \mathrm{~s}$, the required time, the condensate water and the power consumption are recorded. The regeneration efficiency and rate are calculated as shown in Fig. 9.

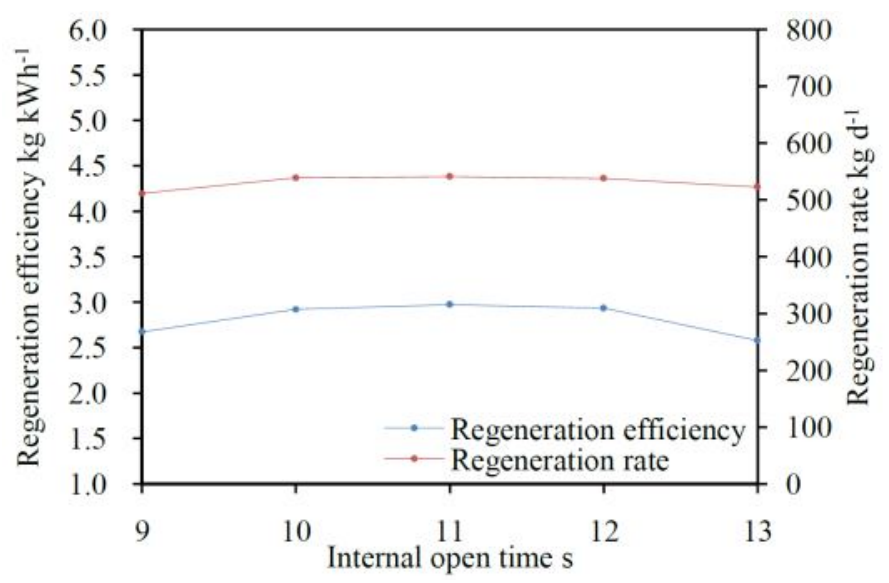

Fig. 9 Regeneration efficiency and rate with different internal open time of outlet electric valve.

As can be seen from Fig. 9, with the increase of valve opening time, the regeneration efficiency and rate show a parabolic trend. Initially, the regeneration efficiency and rate are $2.67 \mathrm{~kg} \mathrm{kWh}^{-1}$ and $511.4 \mathrm{~kg} \mathrm{~d}^{-1}$ respectively. When the opening time increases to $11 \mathrm{~s}$, the regeneration efficiency and rate reach to the highest values, $2.97 \mathrm{~kg}$ $\mathrm{kWh}^{-1}$ and $541.3 \mathrm{~kg} \mathrm{~d}^{-1}$ respectively. When the opening time further increases to $13 \mathrm{~s}$, the regeneration efficiency is decreased to $2.58 \mathrm{~kg}$ $\mathrm{kWh}^{-1}$ and the regeneration rate is decreased to $522.7 \mathrm{~kg} \mathrm{~d}^{-1}$. The reasons for this phenomenon is that in the case of the same number of cyclic groups, with the increase of interval time, the amount of dilute solution inhaled increased, the demand for regeneration heat is increased, and the power consumption is increased. Meanwhile the increase of dilute solution intake leads to the increase of condensing water to a certain extent. Therefore, the regeneration efficiency and rate of the solution have the maximum value.

\section{(2) Performance with different inlet solution temperature}

In this condition, the internal open time is $11 \mathrm{~s}$, and the concentration of solution is $30 \%$. The outside water temperature of the electric heater is set at $95{ }^{\circ} \mathrm{C}$ and the vacuum pressure of the system is 0.83 bar. By changing the inlet solution temperature from $24{ }^{\circ} \mathrm{C}$ to $48{ }^{\circ} \mathrm{C}$, the required time, the condensate water and the power consumption are recorded, and the regeneration efficiency and rate are calculated as shown in Fig. 10.

As can be seen from Fig. 10, with the increase of the inlet solution temperature, the regeneration efficiency and rate of the solution are increased first and then decreased. Initially, the regeneration efficiency and rate of the solution are $3.26 \mathrm{~kg} \mathrm{kWh}^{-1}$ and $529 \mathrm{~kg} \mathrm{~d}^{-1}$ respectively. When the inlet solution temperature rises to $38{ }^{\circ} \mathrm{C}$, the regeneration efficiency reaches to $3.34 \mathrm{~kg} \mathrm{kWh}^{-1}$ and the regeneration rate reach to $613 \mathrm{~kg} \mathrm{~d}^{-1}$. However, when the inlet solution temperature further rises to $48{ }^{\circ} \mathrm{C}$, the regeneration efficiency is $2.94 \mathrm{~kg} \mathrm{kWh}^{-1}$ and the regeneration rate is $581 \mathrm{~kg} \mathrm{~d}^{-1}$. The reason for this phenomenon is that the increase of inlet solution temperature makes the regeneration heat demand and power consumption decrease. At the same time, the increase of inlet solution temperature reduces the driving force of heat and mass transfer during the condensing process, resulting in the decrease of condensate water and the increase of operation time. Therefore, the regeneration efficiency and rate have the maximum value.

(3) Performance with different inlet solution concentration

In this condition, the internal open time is $11 \mathrm{~s}$, and the inlet solution temperature is $30{ }^{\circ} \mathrm{C}$.The outside water temperature of the 


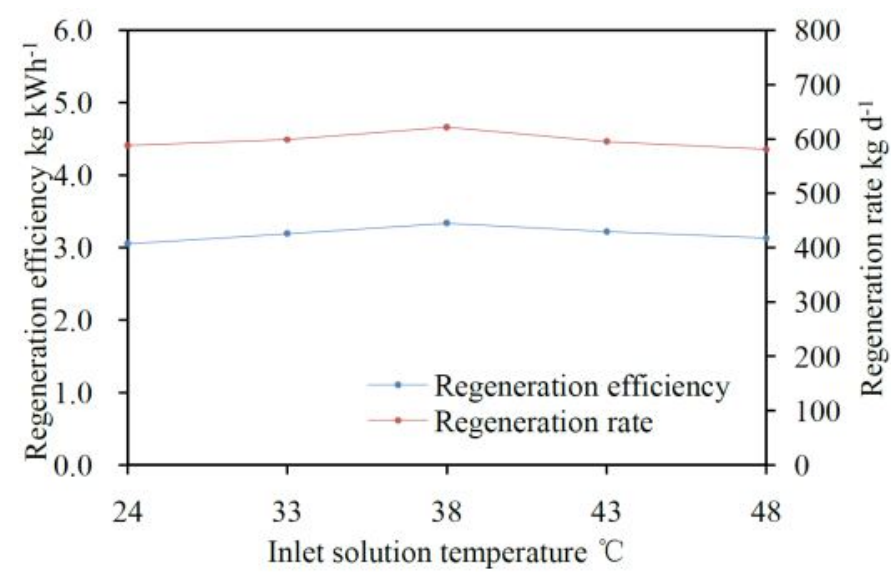

Fig. 10 Regeneration efficiency and rate with different inlet solution temperature.

electric heater is set at $95{ }^{\circ} \mathrm{C}$ and the vacuum pressure of the system is 0.83 bar. By changing the mass concentration of ethylene glycol solution $(0 \sim 37 \%)$, the required time, the condensate water and the power consumption are recorded, and the regeneration efficiency and rate are calculated as shown in Fig. 11.

As can be seen in Fig. 11, with the increase of solution concentration, the regeneration efficiency and rate of the solution are increased first and then decreased. Initially, the regeneration efficiency is $3.29 \mathrm{~kg} \mathrm{kWh}^{-1}$ and the regeneration rate is $651.9 \mathrm{~kg} \mathrm{~d}^{-1}$. When the solution concentration reaches to $18.5 \%$, the regeneration efficiency and rate reach to the maximum value, $4.28 \mathrm{~kg} \mathrm{kWh}^{-1}$ and $748.9 \mathrm{~kg} \mathrm{~d}^{-1}$ respectively. However, when the concentration of the solution further is increased to $37 \%$, the regeneration efficiency is decreased to $3.44 \mathrm{~kg}$ $\mathrm{kWh}^{-1}$ and the regeneration rate is decreased to $688.1 \mathrm{~kg} \mathrm{~d}^{-1}$.

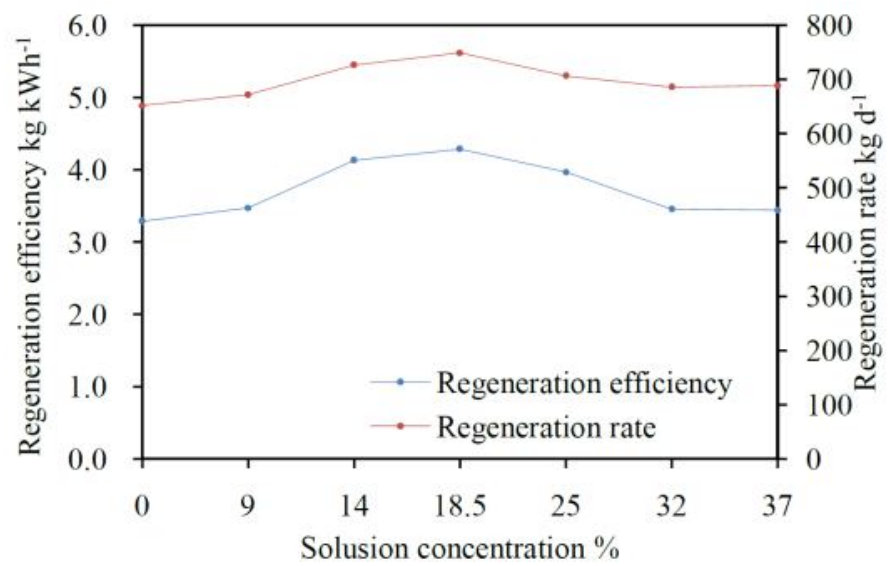

Fig. 11 Regeneration efficiency and rate with different solution concentration.

The reason for this phenomenon is that the regeneration is a dynamic process, which is composed with boiling process and condensation process at low pressure. The two processes are interacted with each other. On the one hand, with the increase of inlet solution concentration, the gradient of boiling surface concentration increases. The concentration of boiling surface solution is higher than that of main stream solution. Therefore, the solution on the boiling surface is moved to the main stream solution driven by concentration difference, which intensifies the disturbance between the fluids and enhances the boiling heat transfer effect. On the other hand, the regenerator condenses water vapor by winding the aluminum fin around the stainless steel tube. When the concentration of the solution is 0 , the condensation effect on the finned tube surface is poor and the drainage is not smooth. With the increase of solution concentration, a small amount of ethylene glycol solute is separated from the solution under the action of water vapor entrainment, and a dynamic hydrophilic film on the surface of the finned tube is formed, which increases the heat transfer coefficient on the heat transfer surface, and the condensation effect of finned tube is improved. Thus, the regeneration efficiency and rate are greatly improved. However, with the further increase of the inlet solution concentration, the thermal conductivity of the solution becomes lower and the viscosity of the solution is increased, which leads to the deterioration of the heat transfer effect of the solution in the tube. As a result, regeneration efficiency and rate are decreased.

\section{(4) Performance with different vacuum condition}

In this condition, the internal open time is $11 \mathrm{~s}$, and the inlet solution temperature is $30{ }^{\circ} \mathrm{C}$. The outside water temperature of the electric heater is set at $95{ }^{\circ} \mathrm{C}$ and the concentration of solution is $30 \%$. By changing the vacuum pressure of the system from 0.825 bar to 0.925 bar, the required time, the condensate water and the power consumption are recorded, and the regeneration efficiency and rate are calculated as shown in Fig. 12.

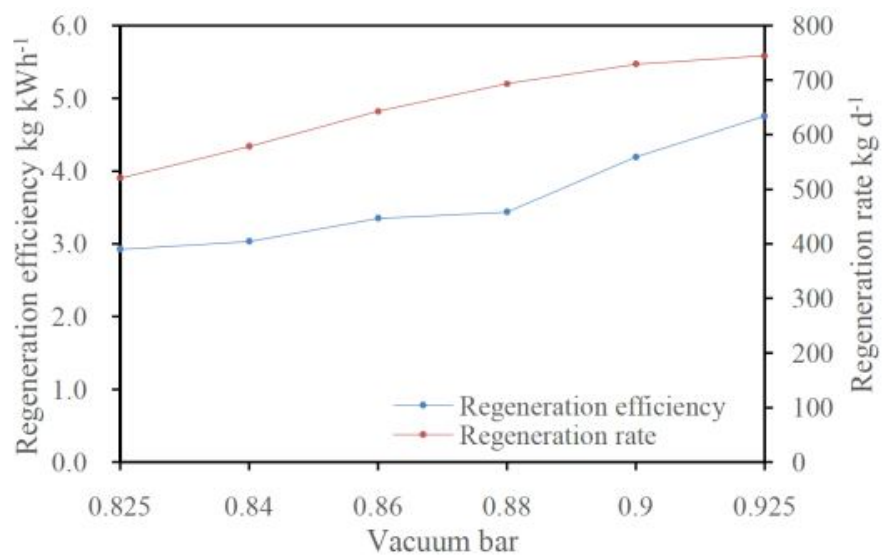

Fig. 12 Regeneration efficiency and rate with different vacuum degree.

As can be seen from Fig. 12, with the increase of vacuum degree, the regeneration efficiency and rate are increased rapidly. When the vacuum degree is 0.825 bar, the regeneration efficiency and rate are $2.93 \mathrm{~kg} \mathrm{kWh}^{-1}$ and $520.5 \mathrm{~kg} \mathrm{~d}^{-1}$ respectively. When the vacuum degree is increased to $0.925 \mathrm{bar}$, the regeneration efficiency and rate reach to the highest value, $4.75 \mathrm{~kg} \mathrm{kWh}^{-1}$ and $744.6 \mathrm{~kg} \mathrm{~d}^{-1}$ respectively. The reason for this phenomenon is that with the increase of vacuum degree, the overheat of the boiling solution is increased and the movement of the fluid is aggravated, resulting in a significant improvement in the regeneration efficiency and rate. During vacuum pumping, the heat dissipation of the pump leads the circulating water temperature to rise, and the vacuum pumping capacity is decreased, which limits the range of vacuum when the regenerative system is running normally. Besides, in the actual operation process, the boiling condensation process in the system makes the system have the vacuum operating upper limit.

\section{Conclusion}

In this paper, a novel solution regeneration system for heat source tower is proposed, and the corresponding experimental setup is built. The effects of inlet and operation parameters on the performance are shown 
as follows:

1) With the increase of solution concentration, the regeneration efficiency and rate of solution are increased first and then decreased, so there is an optimum value. On the basis of this test, under the given operation mode, when the mass concentration of ethylene glycol is $18 \%$, the efficiency of solution regeneration reaches to the maximum value.

2) The vacuum pressure of the system has a great influence on the regeneration efficiency and rate of solution. With the increase of the vacuum pressure, the regeneration efficiency and rate are improved, but the operational reliability is affected when the vacuum pressure is very high.

3) The regeneration rate is increased first and then decreased with the increase of inlet temperature. When the inlet solution temperature is $38{ }^{\circ} \mathrm{C}$, the solution regeneration efficiency reaches to the maximum value.

4) The regeneration efficiency and rate reach to the maximum value when the internal open time of the electric heater outlet valve is $11 \mathrm{~s}$.

The research on the high efficiency heat source tower solution regeneration system shows that the solution regeneration efficiency of the unit can reach to $4.75 \mathrm{~kg} / \mathrm{kWh}$. Based on the latent heat of water vaporization with $2500 \mathrm{~kJ} / \mathrm{kg}$, The maximum efficiency of the electric heating regeneration method can only reach to $1.44 \mathrm{~kg} / \mathrm{kWh}$ $(3600 / 2500=1.44)$. The above research provides data support for the industrial application of the device.

\section{Acknowledgements}

This work is supported by Nanjing Institute of Technology Research Start Foundation (YKJ201606), supported by Outstanding Science and Technology Team Research Innovative in Jiangsu, supported by efficient utilization energy resources research center in Jiangsu.

\section{Nomenclature}

Qc Condensation heat transfer rate $\mathrm{W}$

$C_{p} \quad$ Specific constant pressure heat capacity $\mathrm{J} /(\mathrm{kg} \cdot \mathrm{K})$

$G \quad$ Flow rate $\mathrm{kg} / \mathrm{s}$

HSTHP Heat source tower heat pump

$K \quad$ Overall heat transfer coefficient $\quad \mathrm{W} /\left(\mathrm{m}^{2} \cdot \mathrm{K}\right)$

A Heat transfer area $\mathrm{m}^{2}$

$r \quad$ Latent heat of vaporization $\quad \mathrm{J} / \mathrm{kg}$

$h_{c} \quad$ heat transfer coefficient $\quad \mathrm{W} /\left(\mathrm{m}^{2} \cdot \mathrm{K}\right)$

$g \quad$ Acceleration of gravity $\mathrm{m} / \mathrm{s}^{2}$

$T \quad$ Temperature ${ }^{\circ} \mathrm{C}$

d Pipe diameter $\mathrm{m}$

$R_{e} \quad$ Reynolds number

$P_{r} \quad$ Prandtl number

$Q_{\varepsilon} \quad$ Boiling heat transfer rate $\mathrm{W}$

$q_{\varepsilon} \quad$ Boiling heat flux $\quad \mathrm{W} / \mathrm{m}^{2}$

$R_{g} \quad$ Gas constant

$M \quad$ Relative molecular mass

$p \quad$ pressure $\mathrm{Pa}$
Greek symbols

$\xi$

$\mu$

$\eta_{0}$

$\lambda$

$\sigma$

$\rho$

Subscript

sa

$i$

$o$

e

$s$

$w$

$m$

l

$v$

Regeneration efficiency $\mathrm{kg} / \mathrm{kWh}$

Liquid evaporation coefficient

dynamic viscosity $\mathrm{Pa} \cdot \mathrm{s}$

Fin Efficiency

Thermal conductivity $\quad \mathrm{W} /(\mathrm{m} \cdot \mathrm{K})$

wall thickness $\mathrm{m}$

density $\mathrm{kg} / \mathrm{m}^{3}$

Saturated air

in

out

electric

solution

wall

Logarithmic mean

liquid

vapor

\section{References}

1. Q. Zhang, C. Xu, Z. Zhang, Y. Chen, C. Liu and L. Hui, J. Hydrol., 2008, 353, 215-227.

2. C. Liang, X. Wen, C. Liu and X. Zhang, Energy Convers. Manage., 2014, 85, 596-602.

3. C. Liang, X. Wen and X. Zhang, J. Chem. Ind. Eng., 2010, 61, 142-146.

4. S. Huang, Z. Lv, C. Liang and X. Zhang, Int. J. Refrig., 2017, 77, 116-127.

5. J. Lu, W. Li, Y. Li, L. Zeng, L. Yang, L. Xie, Q. Li and M. Wang, Energ. Buildings., 2017, 145, 318-330.

6. X. Wen, C. Liang and X. Zhang, Build. Environ., 2012, 57, 205-213.

7. X. Wen, C. Liang, C. Liu and X. Zhang, J. Chem. Ind. Eng., 2011, 62, 32423247.

8. X. Wen, C. Liang, X. Zhang, Y. Zhang and X. Zhou, J. Chem. Ind. Eng., 2011, 62, 901-907.

9. X. Wen, C. Liang, C. Liu and X. Zhang, J. Chem. Ind. Eng., 2012, 63, 23982404

10. N. Li, W. Zhang and L. Wang, ICMTMA, 2011, 135-138.

11. X. Liu, Y. Jiang and X. Yi, Renew. Energ., 2009, 34, 209-216.

12. M. Kim, J. Park and J. Jeong, Appl. Therm. Eng., 2015, 89, 717-726.

13. L. Zhang, X. Liu, H. Wei and X. Zhang, Energ. Buildings., 2018, 158, 150161

14. L. Zhang, X. H. Liu and X. S. Zhang, Energy, 2017, 141, 661-672.

15. Y. Yin, X. Zhang, D. Peng and X. Li, Int. J. Therm. Sci., 2009, 48, 16641671.

16. Y. Yin and X. Zhang, Build. Environ., 2010, 45, 1799-1807.

17. S. Nada, Int. J. Therm. Sci., 2017, 113, 10-19.

18. D. Peng and X. Zhang, Renew. Energ., 2009, 34, 699-705.

19. X. She, Y. Yin and X. Zhang, Appl. Therm. Eng., 2016, 95, 79-94.

20. X. She, Y. Yin and X. Zhang, Energ. Buildings., 2017, 88, 288-302.

21. S. Huang, Z. Lv, X. Zhang and C. Liang, Energ. Buildings., 2018, 164, $77-$ 86.

22. Q. Cheng and W. Xu, Energy, 2017, 140, 240-252.

23. Q. Cheng, X. Zhang and S. Jiao, Energ. Buildings., 2017, 155, 475-483.

24. E. Farrell, M. Hassan, R. Tufa, A. Tuomiranta, A. Avci, A. Politano, E. Curcio and H. Arafat, Appl. Energ., 2017, 187, 390-409.

25. X. Li and X. Zhang, Sol. Energ., 2009, 83, 2195-2204.

26. X. Li, X. Zhang and S. Quan, Appl. Energ., 2011, 88, 4908-4917.

27. K. Khoudor, G. Kamel and G. Nesreen, Appl. Energy, 2015, 138, 121-132. 
28. O. Scialdone and A. Albanese, J. Electroanal. Chem., 2013, 704, 1-9.

29. R. Kwak, G. Guan, W. Peng and J. Han, Desalination, 2013, 308, 138-146.

30. X. Gao, Q. Gu, J. Ma and Y. Zeng, Energy, 2018, 143, 658-665.

31. C. Gu, Z. Min and H. Hong, J. Chem. Ind. Eng., 2014, 33,30-35.

32. D. Yang, J. Tan, Y. Wang, Y. Jiang and X. Gao, J. Chem. Ind. Eng., 2015, 34, $4120-4125$
33. L. Gao, K. Zhang, B. Dong and Z. Xing, Chem. Ind. Eng. Prog., 2014, 33, 3112-3117.

34. C. Yu, X. Ma, Z. Lan and J. Wu, J. Chem. Eng. Chin. Univ., 2012, 26, 19-24.

35. Q. Luo, Q. Bi, Y. Han and Q. Zhang, J. Chem. Ind. Eng., 2016, 64, 20012006.

36. S. Deng, T. Zou, T. Zhang, M. Wang and Y. Han, J. Vac. Sci. Technol., 2015, 35, 544-549. 